\title{
Pomakların Dili Üzerine Bir İnceleme
}

\section{A Study on the Language of Pomaks}

Engin Y1lmaz

\section{Öz}

Balkan coğrafyası sakinleri, nüfusları nispeten az olmakla birlikte, çeşitlilik bakımından oldukça zengindir. Balkanlarda, bugünkü Yunanistan'ı da sınırları içerisine alan coğrafi bölge, Türk milleti için tarihî, siyasi, sosyal ve kültürel açıdan son derece önemlidir. Osmanlılardan çok önceleri bölgeye yerleşen Gagavuz, Kuman-Kıpçak, Peçenek gibi Türk boylarının akıbeti Türk tarihi açısından önemli bir problematik olarak görülmektedir. Balkanlarda Bulgarlar, Sirplar, Yunanlilar, Arnavutlar, Boşnaklar ve Hırvatlar gibi var olan milletlerin kökenleri haklarında, istisnai iddialar dışında aşağı yukarı ortak kanaatler varken, Pomaklar, Goralılar ve Torbeşler'in kökenleri hakkında, genel bir kabul yoktur. Bu çerçevede Sırplar; Pomaklar, Torbeşler ve Goralılar ile ilgili olarak "Müslümanlaştırılmış Sırplar", Makedonlar; "Müslümanlaştırılmış Makedonlar", Bulgarlar; "Müslümanlaştırılmış Bulgarlar" şeklinde tezler ileri sürmektedir. Pomaklar, bugün itibarıla Yunanistan, Bulgaristan ve Makedonya'nın dağlı bölgelerinde yoğunlaşmış, kimlik ve yaşam mücadelesi vermektedir. Pomakların tarihi, kökeni, bugün iskân hâlinde bulundukları bölgeye gelirken izledikleri göç yolları ve kullandıkları dil tartışmalıdır. Kanaatimizce bu mesele ile ilgili ortaya atılan tezler, akademik ve tarafsız olmaktan ziyade, politik ve ideolojik bir karakter taşımaktadır. Konunun aydınlatılmasında ortaya konulan Bulgar, Sırp, Yunan ve Makedon kaynaklarının objektif olduğunu söylemek mümkün değildir. Bu itibarla, yaptığımız saha araştırması çerçevesinde, Bulgaristan'da ve Yunanistan'da yaşayan Pomaklar ile doğrudan görüşmeler yapılmış, sosyo-kültürel yapı, dil kullanımları tespit edilmiş ve elde edilen bulgular karşılaştırmalı olarak incelenmiştir. Sonuç olarak, yukarıda adı geçen tezlerin karşısında, tarihî gerçeklere daha uygun olan "Türk Tezi”nin de işlenmesi ve gündemde tutulması gerektiği düşünülmektedir.

Anahtar kelimeler: Pomaklar, Pomakça, kimlik, dil, saha araştırması

\footnotetext{
* Prof. Dr. Sakarya Üniversitesi, Fen-Edebiyat Fakültesi, Türk Dili ve Edebiyatı Bölümü öğretim üyesi, eyilmaz@sakarya.edu.tr
}

Bu makale iThenticate sistemi tarafından taranmıştır.

Makale Gönderim Tarihi: 13 Mart 2021 


\section{Abstract}

The inhabitants of the Balkan geography are rich in diversity, although their population is small in complex. In the Balkans, the geographic region that is included in today's Greece is a very historical, political, social and historical region for the Turkish nation. Although there have been agreed decision about the origin of these nations like Bulgarians, Serbians, Greeks, Albanians, Bosnians and Croatians apart from few exceptions, there hasn't this general acception about the origins of Pomaks, Gorani and Torbesh. In this point, while Serbians, Bulgarians and Macedonians claim that Pomaks, Torbeshs and Goranies are Islamized Serbians, Macedonians and Bulgarians, even Russians believe that these nations are Muslims, whose origin date back to Slavic. Today Pomaks are mostly in the highlands of Greece and Bulgaria, and they have struggled for their survivals and identities. Histories, origin, their migration route for their today's settlement place of Pomaks are controversial issue, and their language is open to debate. Thesis about this issue are rather than being academic, they are politic and ideologic. In the enlightment of the topic, we cannot easily say sources of existing Bulgarian, Serbian, Grek and Macedonian are objective. In this regard, the field work which was made by us, we directly interviewed with Pomaks and identified their language and socio-cultural structure and the results were resolved. As a result, it is thought that "Tukish Thesis", which is more suitable for historical facts, should be proceessed and kept on the agenda in front of the theses mentioned above.

Key Words: Pomaks, Pomak language, identity, language, field researche 


\section{Giriș}

Balkan coğrafyası sakinleri, nüfusları nispeten az olmakla birlikte, çeşitlilik bakımından oldukça zengindir. Balkanlarda, özellikle bugünkü Yunanistan'1, Bulgaristan'1, Kuzey Makedonya'yı ve birçok etnisiteyi içerisine alan Eski Yugoslavya bölgesi Türk milleti için tarihî, siyasî, sosyal ve kültürel açıdan son derece önemlidir. Osmanlılardan çok önceleri bölgeye yerleşen Gagavuz, Kuman-Kıpçak, Peçenek gibi Türk boylarının akıbeti Türk tarihi açısından önemli bir problematiktir. Nitekim, Lozan'dan beri “resmi azınlık" statüsünde yaşamakta olan "Batı Trakya Türkleri” başta Rodos olmak üzere "12 Ada Müslüman Türkleri”, Türkçeyi ikinci dil olarak kullanan ve bugünkü sayıları 70.000’i bulan İstanbul ve Anadolu Rumları da mevcuttur. Balkanlarda; Bulgarlar, Sırplar, Yunanlılar, Arnavutlar, Boşnaklar ve Hırvatlar gibi mensuplarının sayısı bakımından diğerlerine göre fazla olan milletler bulunmakla birlikte, nüfusları bu milletlerinki kadar olmayan Romlar, Aşkalililer, Ulahlar gibi milletler de vardır. Pomaklar, Bulgaristan, Batı Trakya ve Doğu Makedonya'da yaşayan Müslüman bir topluluktur. Tarihî belgeler incelendiğinde, -Pomaklarla ilgili Yunan tezi, Makedon tezi ve Sırp tezi ileri sürülmekle birlikte- XI. yüzyılda Orta Asya ve Kafkaslar'dan Balkanlar'a göç eden Kuman Türkleri'nin bakıyeleri olduğunu savunan Türk tezinin de mevcudiyetini zikretmek mümkündür. Nitekim, Kuman Türkleri’nin XI. yüzy1lda Balkanlar'a geldikleri, Pirin ve Vardar Makedonyası'yla Rodoplar'a yerleştikleri bilinmektedir. Kuman Türkleri, bazı bölgelerde Slav unsurlarıyla karışarak büyük ölçüde ana dillerini kaybetmelerine rağmen, geleneklerini korumayı başarmıştır. XI.-XIV. yüzyıllarda güneyden Müslüman Türklerin Balkanlar'a gelişiyle Kumanlar'ın çoğu eski dinlerini terk ederek İslâmiyet'e geçmiştir (Memişoğlu, 2007: 320). Pomakların Türkiye'ye gelişi 1878 yılı Osmanlı-Rus savaşından sonra ve izleyen yıllarda yaşanan göçlerle yoğunluk kazanmıştır (Özcan, 2013: 50). Başta Edirne ve Kırklareli olmak üzere Bursa, Eskişehir, İzmir, Manisa gibi illerde yaşayan Pomaklar, tıpkı Boşnak, Hırvat, Sırp, Bulgar, Yunanlılar gibi kadim bir halktır (Gençkal ve Beşiroğlu, 2014: 835).

\section{Kavramsal Çerçeve}

\section{Pomak adının anlamı}

Pomak, adını ilk olarak 1882 yılında F. Kanitz açıklamıştır. Kanitz, Slavca "pomoçi” (yardım etmek) fiilinin "pomagaçi” (yardımcılar) şeklinden geliştiğini ve Pomakların Türk ordusunda yardımcı görevlerde bulunmalarından dolayı bu adı aldıklarını öne sürmektedir. Pomak isminin, 14. asırda Anadolu'dan Balkanlara gelen soydaşlarına maddî ve manevî yönden 
destek sağlayan ve Osmanlı ordusunun "öncü” ve "ileri” keşif kollarında aktif olarak görev yapan Kumanlara "yardım eden”, “yardımcı” anlamını ifade etmek üzere Slavlar tarafından verildiği de ifade edilmektedir (Alp, 2008: 24-25).

\section{Pomakların kökeni meselesi}

Kaynaklarda, Orta Asya'dan göç eden Türk kavimleri arasında sayılan Hunlar, Avarlar, Peçenekler ve Kumanlar'ın, Karadeniz'in kuzeyinden göç ederek Balkanlara ve Doğu Avrupa'ya yerleştiklerini görmekteyiz (Hersak, 2002: 221-247). Tarihî, kültürel ve filolojik kaynaklar ve belgeler, bize Pomakların Orta Asya ve Kafkaslar'dan Balkanlar'a göç eden Kuman Türkleri'nin torunları olduğunu düşündürmektedir. Nitekim, Peçenek ve Kumanlar, Karadeniz'in kuzeyinde ve Doğu Avrupa'da devlet kuramamakla birlikte geniş alanlara nüfuz etmişlerdi. Gerek Rus Knezliklerinin kendi aralarındaki mücadelelerinde, gerek Bizans'ın kendi içinde ve komşu devletlerle olan mücadelelerinde Peçenek ve Kumanlar, yardımları alınmak için sürekli kendilerine başvurulan silahlı kuvvetler olarak öne çıkmışlardır (Pritsak, 2002: 509-521). Ancak, 1091 y1lında Kumanların desteğini alan Bizans, Peçeneklere Lebunium'da ağır bir darbe vurarak, onların tarih sahnesinden çekilmelerine sebep olmuştur. $\mathrm{Bu}$ yenilgiden sonra birçok Peçenek ölmüş, kalanlar da Balkanlara dağılmıştır. Böylece Balkan bölgesinde nüfuz, bir süre Kuman-Bizans etkisinde kalmışsa da Pomakların yaşadığ Rodoplar ve Pirinler daha sonra tarihî süreç içerisinde Bizans, Bulgar ve Sırp nüfuz alanları içinde kalmıştır. Böylece, Osmanlıların 14. yüzyılın sonları ve 15. yüzyılın başlarındaki gelişlerine kadar Pomaklar yüzyıllarca Bizans, Sırp ve özellikle Bulgar egemenliğinde yaşamıştır. Bu nedenle de başta dilleri olmak üzere birçok özelliklerini yüzyıllar boyunca hâkimiyetleri altına girdikleri Bulgarların baskısı ile değiştirmek zorunda kalmıştır (Alp, 2008: 24-25).

Saha araştırmamıza konu olan "Pomaklar”ın kökeni ile ilgili başlıca üç tez söz konusudur:

a) Bulgar Tezi: Pomakların, Bulgar kökenli olduklarına dair ortaya atılan tezin temel dayanağını lengüistik tespit oluşturmaktadır. Pomakçanın; Güney Slav dilleri içinde yer alan Bulgaro-Macedonian dil grubu içinde yer almasına istinaden, onların "Müslüman-Bulgar" olduklarıdır. Ancak, sadece dil birlikteliği açısından, her iki toplumun kan bağının olduğunu veya her iki toplumun da Slav ırkından geldiğini savunmak; gerçekçi bir teori değildir. 
b) Yunan Tezi: Bu teze göre; Pomaklar, çok eski Trakyalı kavimlerin soyundan gelmektedir. Pomaklar; önceleri Helenleşmiş, Latinleşmiş sonraları Slavlaşmış, dinsel olarak önce Hıristiyanlaşmış daha sonraları Müslümanlaşmış bir kavimdir. Dağlık bölgelerde yerleşerek, saflıklarını korumuşlardır. Pomak’ın, Eski Yunanca “pomax” (içkici) kelimesinden türediği de iddia edilmektedir.

c) Makedon Tezi: Bu teze göre; Pomaklar'ın, yine kullandıkları dilleri delil gösterilerek Müslüman Makedon oldukları iddia edilmektedir.

Eğer Pomaklar, Bulgarların iddia ettiği gibi Müslüman Bulgarlar ise neden Bulgarlar gibi Bulgarcayı konuşamamaktadırlar? Yine, gerçekten Müslüman Bulgarlar iseler, neden Bulgarlar gibi, Bulgarcayı değil de Bulgarlar tarafından "bozuk Bulgarca" olarak tanımlanan Pomakçayı konuşmaktadırlar. Öte yandan Pomaklar asimile olup Bulgarcaları bu yüzden bozulmuş ise, Bulgarların Bulgarcaları neden bozulmamıştır? Pomakların dillerindeki bozulma, onların Müslüman olmalarına bağlanacaksa eğer bu da ciddi bir veri değildir. Çünkü, Pomakçadaki Arapça oranı yaklaşık \%10 seviyesindedir. Bu sebeplerle, Pomaklara, sadece konuştukları dilin Bulgarcaya benzemesi nedeniyle Bulgarlık iddialarında bulunmak çok erken bir teşhis olacaktır. Bu nedenle, daha fazla delil ele alınarak gözden geçirilmeden, Pomaklar hakkında Bulgarlık iddiasında bulunmak, bilimsel sonuç taşımaktan uzak olacaktır. Ayrıca bu konuda ulaşılmış verileri, ele geçirilmiş delilleri sunmadan, dikkat çekilmesi gereken önemli bir nokta da, kendilerine kabul etmediği başka bir millet aidiyeti atfedilen milletin iradesinin ne yönde olduğunun dikkate alınması mecburiyetidir.

\section{Pomakça}

Pomaklarla ilgili en çok istismar edilen konuların başında dilleri gelmektedir: Pomakça. Pomakçanın içinde yüksek oranda Slav kökenli kelimenin bulunması Pomakların Türk olmadıklarına dair tezin temelini oluşturmaktadır (Memişoğlu, 2007: 320). Ancak, bu durumun asıl nedeninin birçok dil için geçerli olan ödünçleme hadisesi olabileceği dikkatlerden kaçırılmamalıdır. Pomakça, fonetik açıdan kulağa hoş gelen ve düzgün bir dil olmamakla beraber, henüz standartlaşmış bir gramer yapısına sahip değildir. Öte yandan Pomakçaya ve Pomaklara ait kendileri tarafından yazılmış bir yazılı tarihî belgeye, herhangi bir edebi esere, kayıta rastlanılamamıştır. Ancak, Alay’ın (2019:26) işaret ettiği üzere, Balkan 
coğrafyasında halk müziği ve halk şiirinin kadim bir ürünü olarak, Pomak toplumu başta olmak üzere birçok Balkan halk kültüründe söylenegelen “pesna”lar dikkat çekicidir.

Konuşulan bir dil olmasına rağmen Pomakçada; rakamların, sayı sayma özelliklerinin, matematiksel ifadelerin; bu dil içinde yaygın bir tanımlanma biçimi yoktur. Sayı sayma dizininde ancak beşe kadar sayılabilir. Beşten sonraki sayı sayma; Türkçe adlandırmalar ile yapılabilmektedir. Diğer bütün matematiksel ifadeler, Türkçedir. Öte yandan Pomakçanın kullanıldığı bölgelere bakıldığında; kelime telaffuzları bakımından, birbirlerine çok yakın yörelerde yaşanılmasına rağmen sanki büyük bir dil ailesi içindeki lehçe farklılıkları gibi farklar mevcuttur. Birbirine çok yakın iki farklı bölgeden bir araya gelen iki kişi, bazen birbirini anlamakta zorluklarla karşılaşabilmektedir. Hatta bölgesel farklılığın yanı sıra; daha dar kapsamlı olarak, yan yana olan komşu köyler arasında bile ciddi kelime farklılıkların olduğu bilinmektedir. Bu meyanda isim, sıfat ve zamirlerin, bölgelere göre farklı kelimeler ile ifade edilmelerine de sık rastlanılmaktadır. Pomakça diye konuşulan birçok varyantın varlığını kabul etmek gerekmektedir. Pomakça için söylenebilecek, Pomakçanın en doğru konuşulduğu, kullanıldığı bir "merkez Pomakça"dan söz etmek şimdilik mümkün görünmemektedir. Pomakça; \%30 Ukrayna, Bulgaristan ve Makedonya Slavcası; \%20 Oğuz Türkçesi; \%15 Nogay Türkçesi; \%10 Arapçadan oluşmaktadır. Çağatay Türkçesi Pomakçayı büyük ölçüde etkilemiştir. Saha araştırmamızda elde edilen bulgular, bu görüşü destekler niteliktedir (Alp, 2008: 24-25).

\section{Araştırma Amaç, Yöntem ve Teknikleri}

\section{Araştırmanın Amaç ve Problemi}

Pomakların tarihi, kökeni, bugün iskân hâlinde bulundukları bölgeye gelirken izledikleri göç yolları ve kullandıkları dil tartışmalıdır. Konu ile ilgili ortaya atılan tezler, akademik ve tarafsız olmaktan ziyade, politik ve ideolojik bir karakter taşımaktadır. Araştırmanın yapılmasındaki temel amaç, Bulgaristan'da ve Yunanistan'da yaşayan Pomaklar ile yapılan doğrudan görüşmeler çerçevesinde, sosyo-kültürel yap1 çözümlemelerinden ve dil kullanımlarından elde edilen bulgular bağlamında konunun aydınlatılmasına katkı sunmaktır.

\section{Araştırma Yöntem ve Teknikleri}

Araştırmamız, saha araştırmasının verilerine dayanmaktadır. 22.07.2011-29.07.2011 tarihleri arasında gerçekleştirilen araştırmamız, Yunanistan'da; İskeçe ili Mustafça Belediyesine 
Küçük Mustafça, Sadnovitsa, Yassıören, Demircik köyleri ile Gümülcine iline bağlı Mehrikoz adlı Pomak köylerinde özellikle yaşlılardan olmak üzere 7 erkek ve 5 kadınla; 12.09.201115.09.2011 tarihleri arasında da Bulgaristan'daki Gotse Delçev iline bağll, Debren, Daynovo, Ribnovo, Bukovo, Leşteni, Osikovo, Kornitsa, Oreşe, Ablanitsa, Kruşevo, Valkosel, Dolno Drano, Ablanitsa, Oreşe adlı Pomak köylerinde yine özellikle yaşlılardan olmak üzere 14 kadın ve 12 erkek olmak üzere toplam 38 kişi ile, Pomakların söz varlığı üzerine mülakat yoluyla "saha araştırması" yapılmış ve elde edilen bulgular, dil kullanımları bakımından karşılaştırmalı olarak değerlendirilmiştir. Yine Kuman-Peçenek bakiyesi olan Makedonya' da Üsküp'e bağlı Drzlovo, Malçişte, Svetova, Koliçane, Pagaruşe köylerinde de 15 erkek ve 11 kadınla yapılan yüz yüze görüşmelerle, dil malzemesi değerlendirmesi açısından görüşülen kişi sayısı 44'ü bulmuştur. Araştırma yapılan coğrafi saha üç ana başlıkta toplanabilir:

a) Balkan (dağlık) bölgesi: Pomak Türklerinin yoğunlukla yaşadığı bölge,

b) Yaka bölgesi: Pomak Türkleri ve Çıtak Türklerinin karma olarak yaşadıkları bölge,

c) Ova bölgesi: Çıtak Türklerinin yoğun olarak yaşadıkları bölge.

\section{Bulgular}

\section{Pomakçadaki Türkçe kökenli kelimeler/kelime grupları}

a) Türkçeden alıntılanan kelimeler: abli (<abla), açık, akşam, alt1, amıca-amıce, ana $+\mathrm{m}$, arkadaş, at, at-1r-lar, ay, ayran, ayrı ayrı, baba, babayko, bakarç, baklava, balluk (<bolluk), bardak, basamak, basma, bayagi (<bayağı), bayram, bebe, bej (<beş), belik, ben-di-sa, beşik, bile, bin, birkaç, bitmek, boğday, boncuk, buba $+\mathrm{m}$, bugün, bukata (gelin), burun, çene (dişin içteki kısmı), çatal, çevirme, çocuk, çubuk, daddırmak (<tattırmak), dağıt-tir-ir-di-k, dakuz (<dokuz), darak, darı, davar, dedo, demek (demek ki), demir, deri, deve, od deve (deve+den), dilenci+ye (dilenciler), doksan, dokunma (zarar), dört, duymak, düdük, duşek, düşeme, elli, ergen, et, fırle, firlet, gec, gene, gümüş, gün, gündüz, güreş, hamut, içki (içecek), içün-için, iki, kalın çörek, kaçamak (mısır unu, eritilmiş tereyağı ve peynirden yapılan bir yemek), karanlık, kardaş, kaymak, kazan, kekele-rsa, kırklama, kırkma, kırğ $(<$ kırk), kırğ bir, kısa, kişi, komşu- 
komşi, kolan, koym-ur-lar, kurşun, kuşak, nene, ocjak, oda, on, öfürmek (<üfürmek), pamuk, pis, pişirmek, sabah, püskül, sarmaşık, sekiz, siğmen (<seğmen), sonra, söndürmek, süs, süt, sütlaç (koyu süt); süylemek, şamar, şindi (<şimdi), şoltiya ( $<$ şilte), tarla, taşımak, tavan, tepsiya, terlik, tumani, tuplamak (<toplamak), tutunca (tütün), tütün, türlü türlü, ulaşık, uluk (<oluk), üj (< üç), yalnız, yapağı, yatak, yavaş yavaş, yemek, yedi, yetmiş, yenge, yoğurt, yufka.

b) Arkaik özellik gösteren Türkçe kelimeler: baldıza, bunar, çetik, elti, güyü, kart, güveyi, sağdıç, torun+i (torunlar), uruk, yaşmak.

c) Türkçe kalıp sözler: Allah razı olsun buyurun, başın (1z) sağolsun, bereket versin, elhamdülillah, hayır olsun (günaydın), heg gidi dey, hoşj geldiniz, şükür Allah'a, ne kullandi-sa hiç (olumsuz yap1).

d) Türkçe kökenli kelimelere Türkçe ekler getirilerek oluşturulan Türkçe kelimeler: amuca+lık (amca çocukları için kullanılır, yeni fonksiyon) ana +çe (anacığım), baba $+c ̧ ı$ (babacı̆̆ım), başta +tı (babası), bir+de, bir+inci, iki+nci, isi+ce, 1lıca, keçi+li, kes-il-mez, tuz+luk, var-di.

e) Türkçe kökenli kelimelerden oluşturulan birleşik yapıdaki kelimeler: adım çöreği, anneanne, ayak kemiği, gelin ata, sira yemek (sıradan yemek) süt parası.

f) Yabancı kökenli kelimelere Türkçe ekler getirilerek oluşturulan kelimeler: akı1 + lı, akılsız, akşam+dan, akşam+leyin, ayn $+\mathrm{i}$, cehil + lık, hasta $+1 \mathrm{k}$, evlat $+\mathrm{l}_{1 \mathrm{k}}$, fırın $+\mathrm{c}$; fukara+lık, hılabe+cı; gerdan+lık, kahve+ci; kep+siz, kurban+çı, merakli+ya, nazar + lik, sabah+1n, sabahle, sabah+leyin, sapun+çe, semer+ci, şen+lik, şüphe+li, temiz+lemek, zorle.

g) Yabancı kökenli kelime ve Türkçe kökenli kelimeler ile oluşturulan birleşik yapıdaki kelimeler: nazar taşı, bir vakıt, mısır ekmeği. 


\section{Pomakçadaki Türkçe dışında bir dilden alıntılanan kelimeler/kelime grupları}

a) Arapça kökenli kelimeler: akraba, ama, asıl, adet, asker, bazitsi (bazıları), berekat (teşekkürler), bismili (besmele), borç, cemiyat, ceneze, cin, çeyiz, çörek, çul, dayma (<daima), dua, duva, elbette, emrallah, evlat, ezan, fakir, fazla, fukara, hayır, hayvane, hazır, hısım, insan, izmet-hizmet, kadife, kamet, kaval, kavad (<kavvad), keferet, kere, kına, kısmet, mavi, maşallah, merhaba (bir kişi varsa), merhabayın (çok kişi varsa), mesela, misafir, misal, misir, muska, muhtar, nazar, nikah, sabah, saltanat, sebep, sefte-sefta (<siftah), sicim, simit, sufra (<sofra), sofra, sülale, sünnet, şerit, tamam-taman, taman, taraf, tas, tayfa (aile), tencere, yani, zaman, zayıf.

b) Farsça kökenli kelimeler: abdest, aynişte (<angişte), bahşiş, biki (<belki), çardak, çeşme, çınar, çinbiş (<cunbiş), çift çift, çoban, çöp, çuval, çünkü, duvar, duşmani (düşmanlar), gul (ince telaffuzlu), hane, hoca, hoce, hüç (<hiç), günah-güneh, hasta, kemer, köşe, nişan, pare, para-pari, pari (para), pazar, pazar, pirinç, şeker, tane, zurne.

c) Slavca kökenli kelimeler: petak, soba.

d) Fransızca kökenli kelimeler: bonbon-bonboni-bonbone, doktor, jaket, kare.

e) İtalyanca kökenli kelimeler: lira (reşat altını).

f) İtalyanca kökenli kelime: çokolade.

g) Rumca kökenli kelimeler: bide (<pide), fener, fürun (<firın)", keramid (<kiremit), semer

h) Yabancı kökenli kelimelere Türkçe ekler getirilerek oluşturulan Türkçe kelimeler: akıl +1 , akılsız, akşam+dan, akşam+leyin, ayn $+\mathrm{i}$, cehil $+1 \mathrm{lk}$, hasta + lik, evlat $+1 \mathrm{k}$, fırın $+\mathrm{c}$; fukara+lık, hılabe+c1; gerdan+lık, kahve+ci; kep+siz, kurban+çı, merakli+ya, nazar + lık, sabah+1n, sabahle, sabah+leyin, sapun+çe, semer+ci, şen+lik, şüphe+li, temiz+lemek, zorle. 
i) Yabancı kökenli kelime ve Türkçe kökenli kelimeler ile oluşturulan birleşik yapıdaki kelimeler: nazar taşı, bir vakıt, mısır ekmeği.

j) Yabancı kökenli kelime ve yabancı kökenli kelimeler ile oluşturulan birleşik yapıdaki kelimeler: zaval vakti, sofra bezi, tri dane, mladata buka, başti (büyükler), maytab $(<$ mahtab).

\section{Sonuç ve Tartışma}

Pomaklar, Torbeşler ve Goralılar'ın dağlık bölgelerde yaşamaları dil incelemeleri açısından elverişli bir durumdur. Çünkü; merkezden uzak olma, ilgili unsurların bölgesel dillerden daha az etkilenmeleri anlamına da gelmektedir. Ayrıca, bu diller arasındaki dil ve kültür bakımından benzerlik dikkat çekicidir. Pomakça olarak adlandırılan dilin henüz bir yazı dili, alfabesi olmadığı da dikkate alınırsa Pomakçanın başka bir dilin etkisi altına girmesi, sentaks yapısının büyük ölçüde benzeşmesi doğal karşılanabilir. Halihazırda, Pomakların kullandıkları dilin bozulmuş bir Bulgarca olduğunu söylemek mümkündür. $\mathrm{Bu}$ durum iki şekilde açıklanabilir:

i) Pomak Türkleri, bask1 ve zorlama sonucu öğrendikleri Bulgarcayı unutmaya başlamıştır, unutmak üzeredir. Yaptığımız saha araştırması çerçevesinde, bu unutulan Bulgarcanın yerini Türkçenin aldığını söylemek mümkündür. Özellikle Yunanistan'daki Pomakların söz varlığı içerisinde Türkçeye daha çok yer verdikleri tespit edilmiştir.

ii) Pomak Türkleri, Bulgarcayı birkaç asırdır öğrenmekte ve kullanmaktadır. Ana dili olan Türkçenin yerini henüz almaya başlayan ve Türkçe ile yapısal olarak benzeşmeyen Bulgarcanın özellikle sentaks yapısı Pomakları zorlamaktadır. Bu durum da, ortaya karma olmakla birlikte Bulgarcaya yakın bir dili çıkarmaktadır.

Yunanistan bölgesindeki Pomaklarda daha çok olmakla birlikte, Bulgaristan bölgesindeki Pomakçada Türkçe kökenli kelimelerin kullanımı yüksek orandadır. Bulgaristan bölgesindeki Pomakçada Türkçe kelimelerin nispeten az olması, Bulgarların baskısı ile açıklanabilecek bir durumdur. Her iki bölgede kullanılan Türkçe kelimeler içinde arkaik özellik gösteren Türkçe 
kelimeler azımsanmayacak miktardadır. Bu hâliyle bile Pomakların Bulgar olma ihtimali son derece zayıftır, çünkü Bulgarlar, Pomakların kullandığı arkaik Türkçe kelimeleri kullanmamaktadırlar. Eğer öyle olsaydı, bu arkaik kelimelerin Türkçe baskısı ile unutulmamasının sağlandığı düşünülebilirdi. Bulgarların, tıpkı Pomaklar kadar arkaik Türkçe kelimeleri bilmemeleri arkaik kelimelerin zorla öğretildiği ihtimalini, bu da Pomakların, bir de bu açıdan Bulgar olma ihtimalini ortadan kaldırmaktadır. Türkçeyi anadili olarak kullanmayan milletlerin bu denli arkaik kelimeleri yoğun olarak kullanmaları normal karşılanacak bir durum değildir. Bu durum onların Türkçeyi anadili olarak kullandıklarının göstergesi olarak değerlendirilmelidir. Öte yandan yabancı kökenli kelimelere Türkçe ekler getirilmesi suretiyle yeni Türkçe kelimeler oluşturulması, yine Pomakların Türkçeyi ana dili olarak kullandıklarının göstergesidir. Yine vurgu yapılmak istenen durumlarda, Türkçenin tercih edilmesi, prestijli dil olarak kullanılması da Türkçenin önemini sergilemektedir. Pomakçada, bazı kelimelere yeni anlamlar yüklenmesi ve bu anlamların Türkçe olması, Türkçe kökenli kelimelerin, arkaik özellik gösteren Türkçe kelimelerin, Türkçe kalıp sözlerin çokluğu, Türkçe kökenli kelimelere Türkçe ekler getirilerek oluşturulan yeni Türkçe kelimeler, Türkçe kökenli kelimelerden oluşturulan birleşik yapıdaki kelimeler, yine Türkçenin önemi ve prestiji ile açıklanabilecek bir durumdur.

Balkan tarihinin karmaşık doğası göz önüne alındığında, Pomakların uzlaşılan bir kökeni olduğu söylenemez. Ancak, tarihî bilgiler, kültürel analizler ve dil incelemeleri göstermektedir ki; Pomaklar, Torbeşler ve Goralılar Türklere, Bulgarlardan da, Yunanlardan da, Makedonlardan da, Arnavutlardan da çok daha fazla yakınlık göstermektedir. Pomaklar, Torbeşler ve Goralılar ile ilgili olarak ciddi kaynaklar ayrılarak ortaya atılan ve savunulan "Yunan Tezi”, "Bulgar Tezi”, "Sirp Tezi”, "Makedon Tezi” bilimsel olarak kanitlanmaya muhtaçtır. Bu tezler karşısında, tarihî gerçeklere daha uygun olan "Türk Tezi”"nin de işlenmesi ve gündemde tutulması gerekmektedir. Bu çalışmanın disiplinlerarası bir anlayışla yürütülmesinin yanında, özellikle “Göç Tarihi”nin ve “Göç Yolları”nın belgelere ve kayıtlara dayalı olarak ortaya konulmasının da son derece önemli olduğu düşünülmektedir. 


\section{Kaynakça}

Alay, Okan (2019). "Balkan ve Trakya Coğrafyasında Köklü Bir Halk Kültürü Varlığ1: Guslarilik (Halk Şairliği) ve Pesna (Halk Ezgisi)". Motif Akademi Halkbilimi Dergisi, Cilt: 12, Say1: 25, ss. 21-30.

Alp, İlker (2008). Pomak Türkleri Kumanlar-Kıpçaklar, Edirne: Trakya Üniv. Yay.

Gençkal, Berkant; Beşiroğlu, Ş. Şehvar (2014). "Pomaklar ve Pesna Geleneğindeki Pentatonizm”. Uluslararası Sosyal Araştırmalar Dergisi, C. 7, S. 33, ss. 835-854.

Hersak, Emil (2002). “Avarlar; Etnik Yaratılış Tarihlerine Bir Bakış”. Türkler Ansiklopedisi, c. 2, Ankara: Yeni Türkiye Yayınları, ss. 221-247.

Memişoğlu, Hüseyin (2007). "Pomaklar”, TDV İslam Ansiklopedisi, c. 34, ss. 320-321.

Özcan, Seren (2013). Pomak Kimliği. Edirne: Ceren Yayıncılık.

Pritsak, Omeljan (2002). "Türk-Slav Ortak Yaşamı; Güneydoğu Avrupa'nın Türk Göçebeleri”. Türkler Ansiklopedisi, c. 2, Ankara: Yeni Türkiye Yayınları, ss. 509-521. 